\title{
El arrepentimento de San Pedro de Francisco Collantes. Restauración y análisis de pigmentos
}

\author{
Oscar Lantes-Suárez, Laura Carrera Nogueiras, Filomena Dorrego Martínez, Joeri Kaal, Vanesa \\ Mariño Calvo y María Antonia Domínguez Lago
}

Resumen: En este trabajo presentamos el proceso de restauración y de análisis de pigmentos del cuadro El Arrepentimiento de San Pedro de Francisco Collantes, un pintor barroco del s. XVII. El proceso de restauración ha permitido devolver su esplendor a la obra que será expuesta de modo permanente en el Museo de Belas Artes de A Coruña, depositaria de la misma. El análisis químico de los materiales presentes en las capas pictóricas, además de permitir la identificación de las mismos constatando que son característicos de la época de la obra, ha justificado la elección del criterio de restauración a seguir que consistirá en respetar la veladura original oscurecida.

Palabras clave: restauración, pigmentos, SEM, Py-GG-MS, THM-GG-MS

\section{The repentance of San Pedro de Francisco Collantes. Restoration and analysis of pigments}

Abstract: We present the process of restoration and analysis of pigments in the painting El Arrepentimiento de San Pedro by Francisco Collantes, a Baroque painter from the 17th century. The restoration process allowed the recovery of the splendor of this work, which will be exhibited permanently in the Museo de Belas Artes de A Coruña. The chemical analysis of the pictorial layers, in addition to allowing their identification, confirmed that the materials used are characteristic of the corresponding traditions, and has allowed selecting the most appropriate criterion to restore the original glaze of the painting.

Keyword: Restauration, Pigments, SEM, Py-GC-MS, THM-GC-MS

\section{O arrependimento de São Pedro de Francisco Collantes. Restauro e análise de pigmentos}

Resumo: Neste trabalho apresentamos o processo de restauro e análise de pigmentos da pintura O arrependimento de São Pedro de Francisco Collantes, um pintor barroco do século XVII. O processo de restauro permitiu devolver o seu esplendor ao trabalho que será exposto permanentemente no Museu de Belas-Artes de A Coruña, o depositário do mesmo. A análise química dos materiais presentes nas camadas pictóricas, além de permitir a identificação dos mesmos, confirmando que são característicos da época do trabalho, justificou a escolha do critério de restauro a ser seguido que consistirá em respeitar a velatura original escurecida.

Palavras-chave: ca Restauro, Pigmentos, SEM, Py-GG-MS, THM-GG-MS 


\section{Introducción}

En el año 2016, el Museo de Belas Artes de A Coruña encarga a la Universidad de Santiago de Compostela (USC) un estudio de dos bienes culturales de sus fondos que se encontraban en proceso de restauración. El estudio concluyó con un informe emitido por la Unidade de Arqueometría (RIAIDT, USC) titulado "Estudio arqueométrico de dos bienes culturales del Museo de Belas Artes de A Coruña: óleo barroco sobre lienzo EI arrepentimiento de San Pedro y escultura de madera dorada y policromada San Benito. 2016". En lo referente al cuadro, se analizaron el material pictórico y parte del marco del cuadro -estuco y pan de oro- así como varios materiales utilizados en la restauración, como barnices y estucos. También se hizo una radiografía completa. En la escultura policromada se analizó el pan de oro que la recubría y se hizo una tomografía. En este trabajo recogemos parte de los resultados de ese estudio, en concreto el análisis de los pigmentos de la obra El arrepentimiento de San Pedro.

El cuadro tuvo al menos un proceso de restauración anterior a su ingreso en el Museo en el año 1951. Posiblemente aquella intervención consistió en un forrado del soporte de tela para eliminar deformaciones, un refuerzo de bordes dañados (iy recortados?), el clavado en bastidor, una limpieza con la eliminación parcial de barniz oxidado, el estucado de lagunas, un repintado de faltas con pintura al óleo y un barnizado final. En tiempos recientes se apreciaba en el cuadro la aparición de nuevas deformaciones en el soporte de tela, la pérdida de adhesión parcial de la tela de forrado, el oscurecimiento de los repintes al óleo -que afeaban enormemente el aspecto de la pintura- $y$ el acusado contraste entre las zonas de luces y sombras de la obra, debido con toda seguridad a una antigua limpieza desequilibrada. Este deterioro hizo recomendable proceder a una nueva restauración para reestablecer el equilibro cromático de la capa pictórica, llevada a cabo por parte de los restauradores del museo y cuya descripción se incorpora en este trabajo.

Destacamos la importancia de este estudio, no por el proceso de restauración y analítico en sí mismo, habitual en centros de cierta relevancia, sino porque es el primer estudio de estas características de una obra perteneciente a la colección del Museo de Belas Artes y que se consigue mediante la colaboración con la Universidad de Santiago de Compostela. Además, la identificación de algunos pigmentos, en especial la veladura verde era fundamental para justificar su no eliminación en la limpieza a pesar de su irreversible pardeamiento.

\section{El autor}

Las referencias que aportan Antonio Acisclo Palomino y Lázaro Díaz del Valle sitúan a Francisco Collantes (Cruz Valdovinos 1997), autor del cuadro, ejerciendo su actividad en Madrid y fijan las fechas de su nacimiento en 1599 y la de su muerte en 1656. Como pintor de cuadros de contenido religioso, sus figuras de santos aislados y de gran tamaño, acusan directamente la influencia del tenebrismo de Ribera, en ellos la potente luz que los ilumina es el principal elemento modelador. El paisaje fue el género que practicó preferentemente y en el que destacó, en un momento en el que la pintura española era considerada como una disciplina menor. Cultivó paisajes puros, sin anécdota alguna, en ocasiones con pequeñas figuras y animales resueltos con acusado realismo y en mayor medida con escenas de carácter religioso entre las que destaca el lienzo titulado, Visión de Ezequiel del Museo del Prado, con evocaciones de arquitecturas clásicas y rasgos naturalistas en el tratamiento de las figuras humanas. Los paisajes en los que se insertan las figuras religiosas denotan la influencia del paisaje flamenco de fines del siglo XVl y la conexión con el estilo italiano de principios del siglo XVII. Son escenarios desarrollados en profundidad en los que se distribuyen pequeñas construcciones, puentes, ríos, troncos rotos y masas oscuras de árboles de follaje tupido que se recortan sobre lejanías luminosas. Francisco Collantes pintó algunos bodegones e incluso temas mitológicos como El incendio de Troya del Museo del Prado. Tanto sus pinturas religiosas como de paisaje fueron demandadas por particulares como se refleja en los inventarios de bienes del siglo XVII en los que se registran abundantes obras de su autoría; se citan, entre ellos, varios países, nombre con el que se conocía la pintura de paisajes, varias representaciones de San Jerónimo, Santiago, Oración en el Huerto y un Apostolado compuesto por 16 lienzos. Para la decoración del Palacio del Buen Retiro en Madrid, Eugenio Cajés tasó en 1634 un conjunto de paisajes de Collantes, en buena parte conservados actualmente en el Museo del Prado. Indicativo también de la alta estimación que tuvo su pintura, es que una de sus obras, Moisés ante la zarza, figurase en la colección de Luis XIV, que pasó después a la colección del Museo del Louvre.

\section{Descripción del bien}

El Arrepentimiento de San Pedro es un óleo sobre lienzo datado entre 1630 y 1656 [figura1]. Sus medidas son 107 x $170,5 \mathrm{~cm}$ sin marco y $188 \times 130 \times 10 \mathrm{~cm}$ con marco. La tela está montada en un bastidor móvil de madera con un travesaño central vertical. El lienzo, con número de inventario 1922, forma parte de la colección estable del Museo de Belas Artes de A Coruña. Fue donado a esta institución por el escritor y poeta Ramón Goy de Silva en el año 1951. Su anterior propietario, Francisco Pérez Asencio, lo prestó para que figurase en la Exposición Iberoamericana de 1929 celebrada en Sevilla y la autoría aportada por el propietario se asignaba entonces a Diego Velázquez (Catálogo del Palacio de Bellas Artes, p. 224), si bien años más tarde quedará argumentada la inconsistencia de esta particularidad. Alfonso Pérez Sánchez atribuye la obra a Francisco Collantes, en el estudio que realiza sobre la obra pictórica del pintor destacando los aspectos compositivos y estilísticos que son distintivos de su expresión artística, 


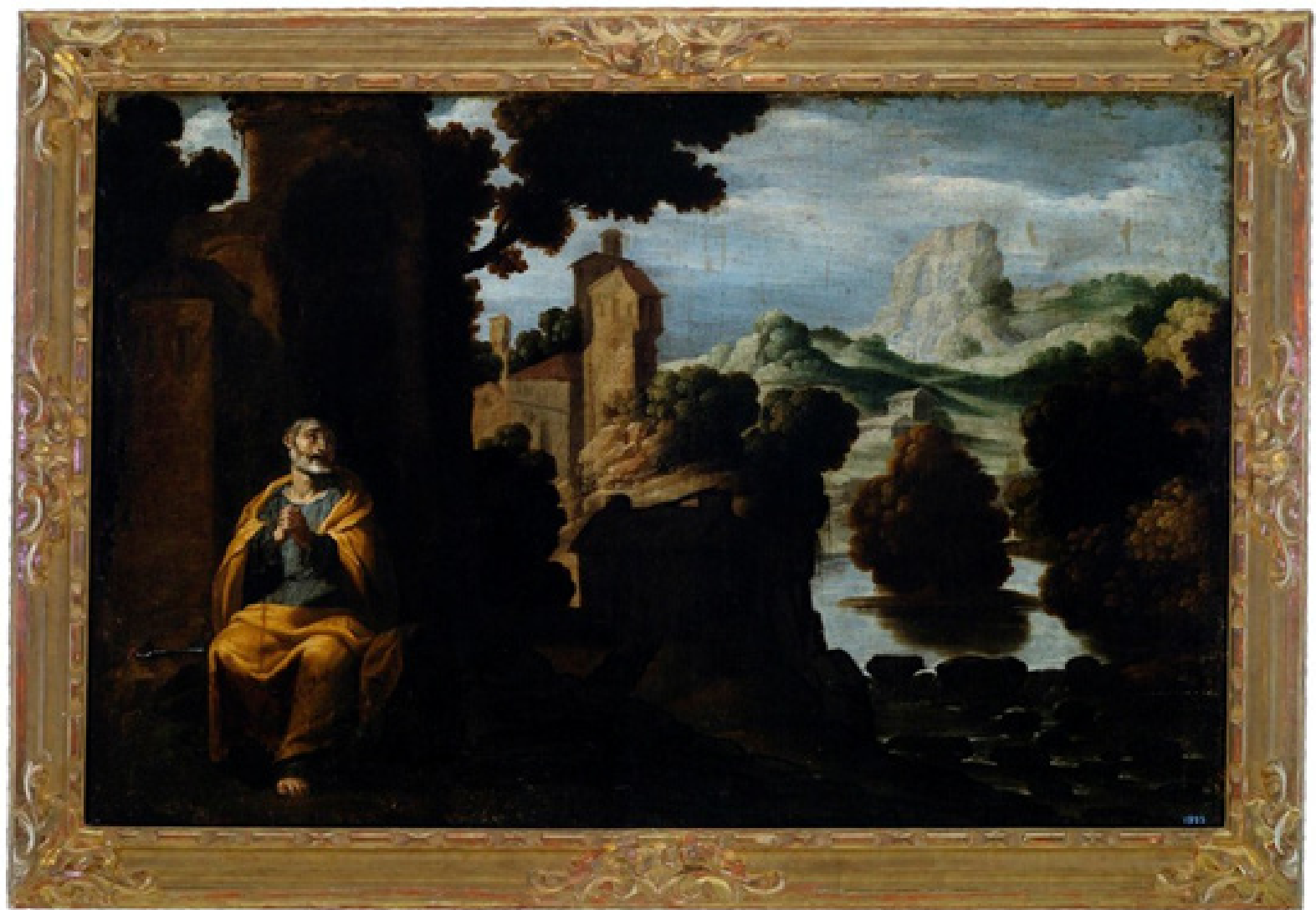

Figura 1.- Fotografía del cuadro El Arrepentimiento de San Pedro.

en concreto el paisaje en el que se inserta la figura del santo (Pérez Sánchez 1962: 259). Igualmente, el lienzo se clasifica como de Collantes en una investigación posterior (Angulo Íñiguez y Pérez Sánchez 1983: 53).

Dicha obra es una muestra de las características principales de la pintura de Collantes, donde su formación tenebrista se manifiesta ampliamente. El cuadro presenta un acentuado claroscuro en primer plano que queda matizado con la apertura de un amplio paisaje, conformado por varios elementos arquitectónicos, peñascos y arboledas tupidas que se recortan sobre el cielo luminoso. El pintor inserta la figura del Apóstol en uno de sus característicos paisajes, jugando con el contraste entre las lejanías plateadas y la figura recortada a contraluz (Pérez Sánchez 2000: 24).

La concepción de la figura remite al modelo creado por José de Ribera en el siglo XVII para representar la aflicción del santo y su actitud penitencial, el rostro alzado y las manos entrelazadas. Con la cabeza calva y la barba corta que serán desde entonces rasgos habituales de su iconografía. La cabeza ligeramente alzada y girada hacia la derecha posiblemente dirigiendo la mirada a la zona de altas lucesy las manos alzadas a la altura del pecho y cruzadas, son un indicativo de que la figura se muestra en un momento de recogimiento o en actitud contrita, suplicando perdón. Igualmente, a la izquierda del personaje y sobre lo que parece ser una roca, se vislumbra una gran llave- hace referencia a las llaves del Reino de los cielos que Jesús le promete (Evangelio de Mateo 16:19). Ese elemento, unido al hecho de que el personaje se encuentre descalzo, orando y lleve barba, nos permiten identificarlo como San Pedro (la palabra Pedro quiere decir conocedor y descalzo; De la Vorágine 2011) y su arrepentimiento. Este episodio, narrado en los Evangelios, sucede después de que San Pedro negase en tres ocasiones conocer a Jesucristo en la noche de su prendimiento. Fue muy difundido en el arte de la Contrarreforma católica ya que su actitud penitencial se mostraba como un ejemplo a seguir por los fieles. Habitualmente, en las imágenes de San Pedro arrepentido, su aflicción se enfatiza mediante el lenguaje corporal: la cabeza está alzada, en el rostro vuelto hacia lo alto las cejas se arquean y los ojos aparecen llorosos, y las manos entrelazadas indican un gesto suplicante de perdón.

\section{Proceso de restauración}

El proceso de restauración que se va a describir en este trabajo se inició en septiembre de 2012 con el desmontaje del marco dorado, la realización de las primeras fotografías para documentar el estado de conservación [figura 2], y la aplicación de técnicas de análisis no destructivas tales como la observación con radiación Ultravioleta y Reflectografía IR. Con estas actuaciones iniciales se pudieron obtener los primeros datos acerca del estado de la capa de barniz 

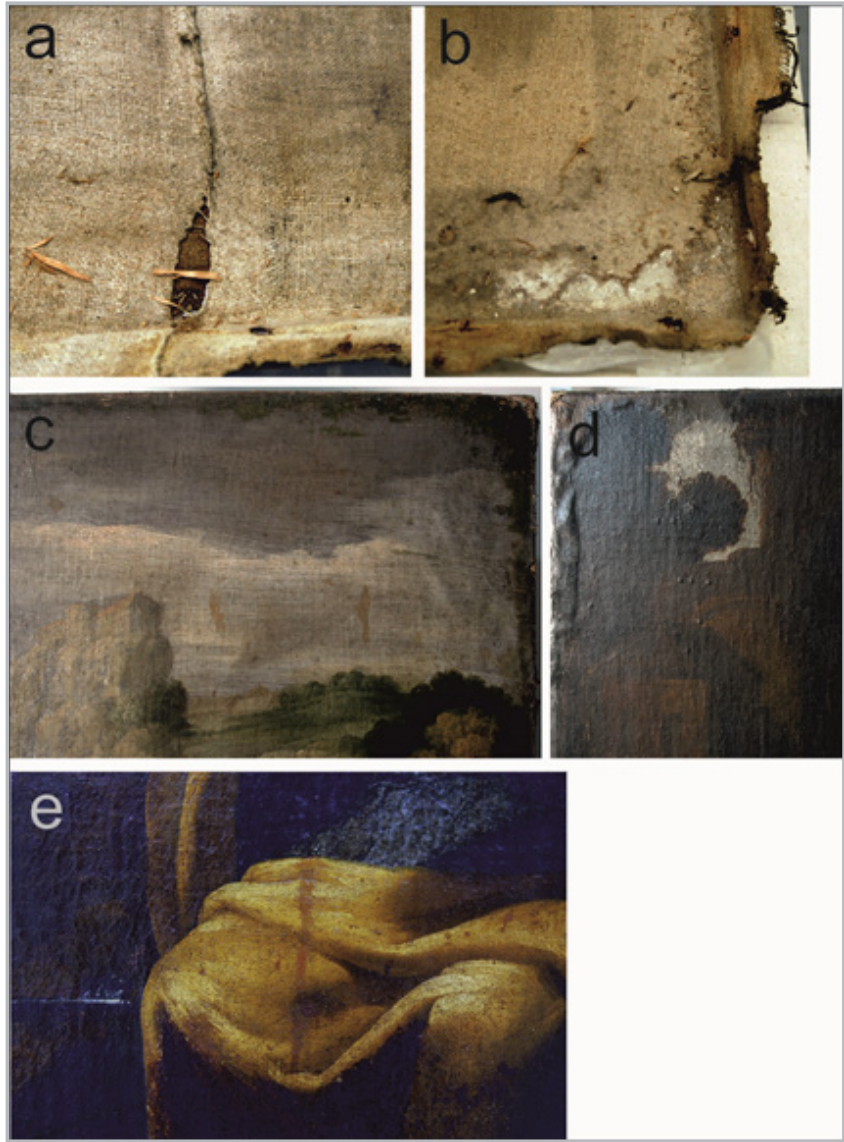

Figura 2.- Estado inicial de la obra; a: descosido en la tela, b: suciedad y alteración en el reverso; c: repintes en cielo y perímetro; d: deformaciones en la esquina superior izquierda; e: repintes sobre el manto.

y de la capa pictórica así como constatar la existencia de repintes invasivos oscurecidos que ocultaban la capa pictórica original.

Una vez documentado el estado de conservación se procedió a empapelar la superficie pictórica con papel japonés y colletta para desclavar el cuadro del antiguo bastidor que estaba levemente atacado por insectos xilófagos y presentaba astillado en la esquina inferior derecha [figura 3]. Retirado el bastidor se inició la limpieza del reverso mediante aspiración. Una vez realizada esta operación se evidenció el debilitamiento y mal estado de la tela de reentelado, que mostraba un desencolado parcial, pérdidas y desgarros en los bordes y en la zona de la costura, muy marcada en el anverso de la tela original. La pérdida de propiedades físicas y mecánicas del adhesivo empleado para la adhesión de ambas telas — gacha - fue determinante para tomar la decisión de la eliminación mecánica de la tela de refuerzo, una vez comprobado el buen estado del soporte original.

La eliminación del antiguo reentelado ha permitido recuperar la visión del reverso original, constatando su excelente estado de conservación. El reentelado consiste en la adhesión de una tela nueva al reverso del cuadro con la finalidad de reforzar la tela original (Villarquide 2001:
145). Se ha utilizado como tratamiento en restauración desde el s. XVI pero, aunque en la actualidad se restringe su aplicación a graves daños que afecten al soporte, antiguamente se generalizó su uso como tratamiento también para consolidación de capa pictórica por lo que muchos cuadros han sido reentelados innecesariamente como parece haber sido también el caso de esta obra. A continuación se procedió a la colocación de bandas perimetrales de tensión de tela de lino sintético desflecados adheridos a los originales con adhesivo sintético para permitir el tensado y clavado del lienzo al nuevo bastidor.

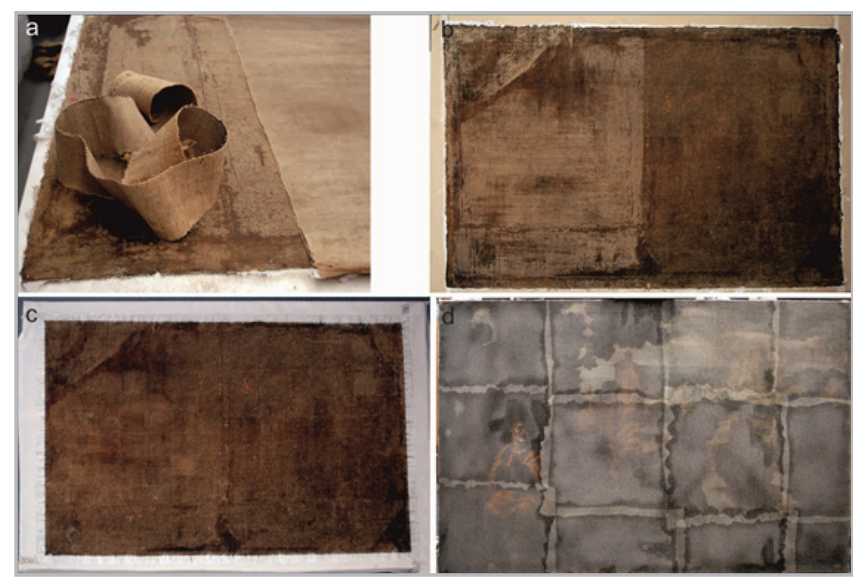

Figura 3.- Eliminación del reentelado, media limpieza y limpieza completa del reverso ( $a, b, c)$. Empapelado de la superficie pictórica (d).

Una vez finalizado el tratamiento del soporte, y tras la retirada del empapelado de la superficie se procedió a la limpieza químico-mecánica empleando mezclas de disolventes aplicados mediante hisopos de algodón [figura 4]. En el transcurso de la limpieza se observó cómo los colores verdes mostraban un pardeamiento que no es deseable adelgazar con el uso de los disolventes por tratarse de la capa oxidada de la veladura original y no de una capa de barniz externo deteriorado. Para estos colores se sospecha la utilización de veladuras de cobre, que bien hoy en día podrían estar trasformadas en resinatos de cobre (desde Van den Berg et al., 2000a, se interpretan los resinatos de cobre como una reacción por deterioro entre el cobre y las resinas más que como un material pictórico aplicado originalmente por el artista). Esta ha sido la hipótesis de partida que ha motivado la realización de una toma de muestras en estos materiales para proceder a su análisis químico, pues esta caracterización es fundamental para la posterior elección del criterio de restauración a seguir.

Paralelamente a la limpieza se procedió a la eliminación de repintes al óleo, realizados en antiguas restauraciones y fuertemente oscurecidos. Estos repintes cubrían áreas bastante más amplias que las lagunas que pretendían ocultar. Para ello, fue preciso combinar el rebajado de estucos antiguos en buen estado pero que excedían los contornos de las lagunas, con la aplicación de nuevo estuco tradicional -a base de yeso mate y cola de conejo 

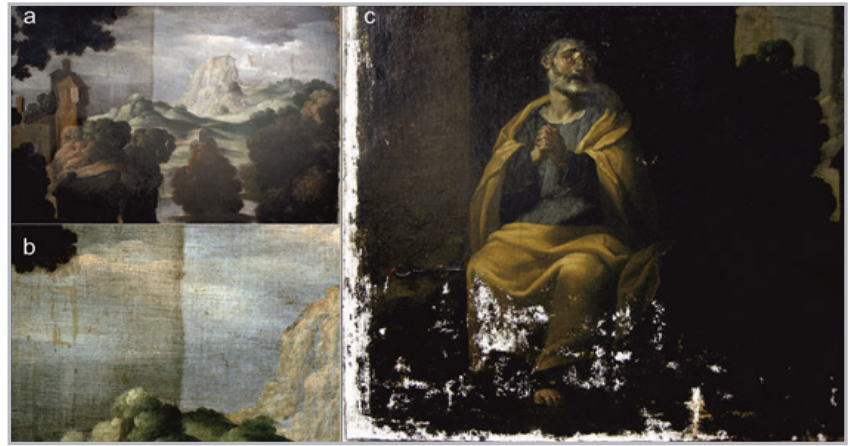

Figura 4.- Proceso de limpieza (a, b; detalles) y estucado (c).

aplicado en caliente a pincel- en lagunas de reciente aparición [figura 4]. Una vez todos los estucos estuvieron rebajados a nivel, se aplicó una mano de barniz de retoque previo al inicio de la reintegración cromática [figura 5]. Ésta fue realizada empleando acuarelas y pigmentos al barniz con técnica de rigattino (Villarquide 2001: 273) esto es, empleando pequeños trazos verticales de colores, aplicados con pinceles finos, que permiten, al acercarse, diferenciar la reintegración de la pintura original. Finalmente se aplicó a toda la superficie pictórica una mano de barniz de resina dammar en caliente con brocha suave a modo de protección final. La imagen final, tras la eliminación de los repintes, permite apreciar la obra con un colorido y luminosidad más parecido a lo que fue en origen [figura 6].
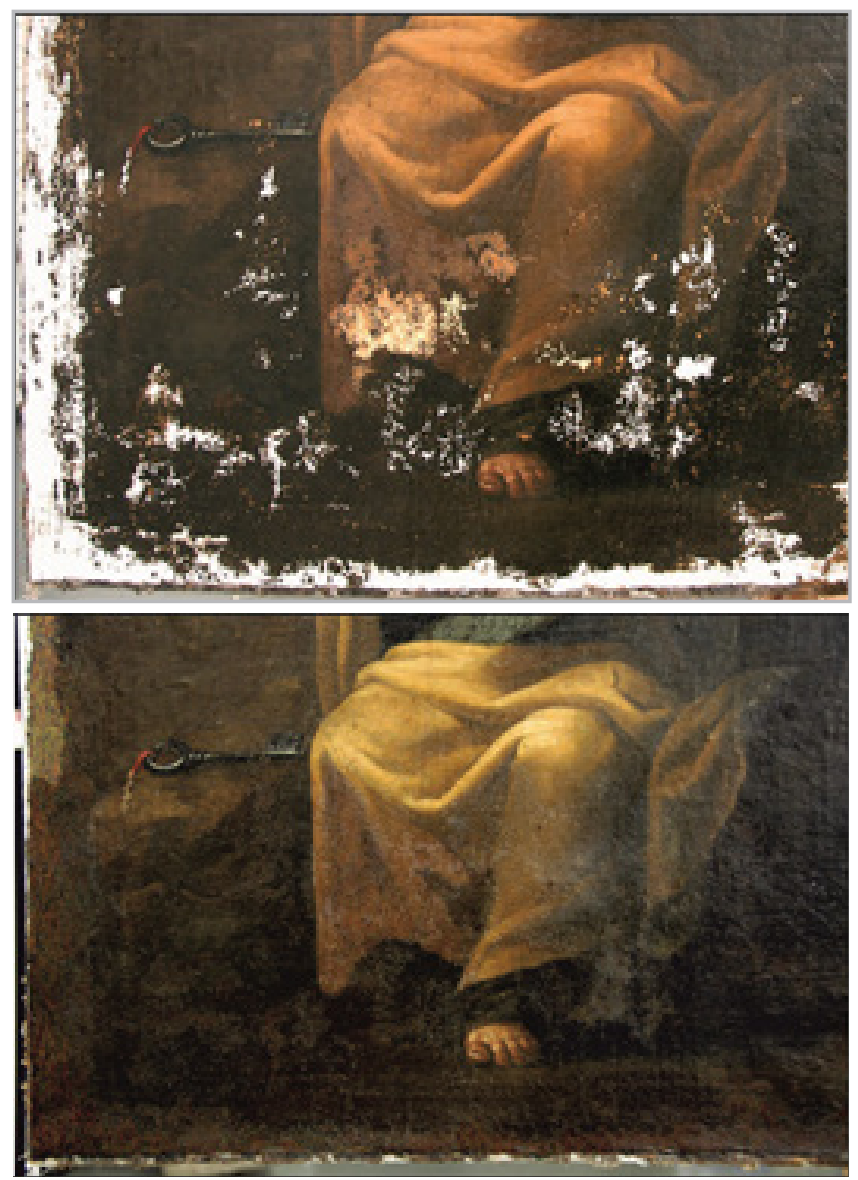

Figura 5.- Reintegración.
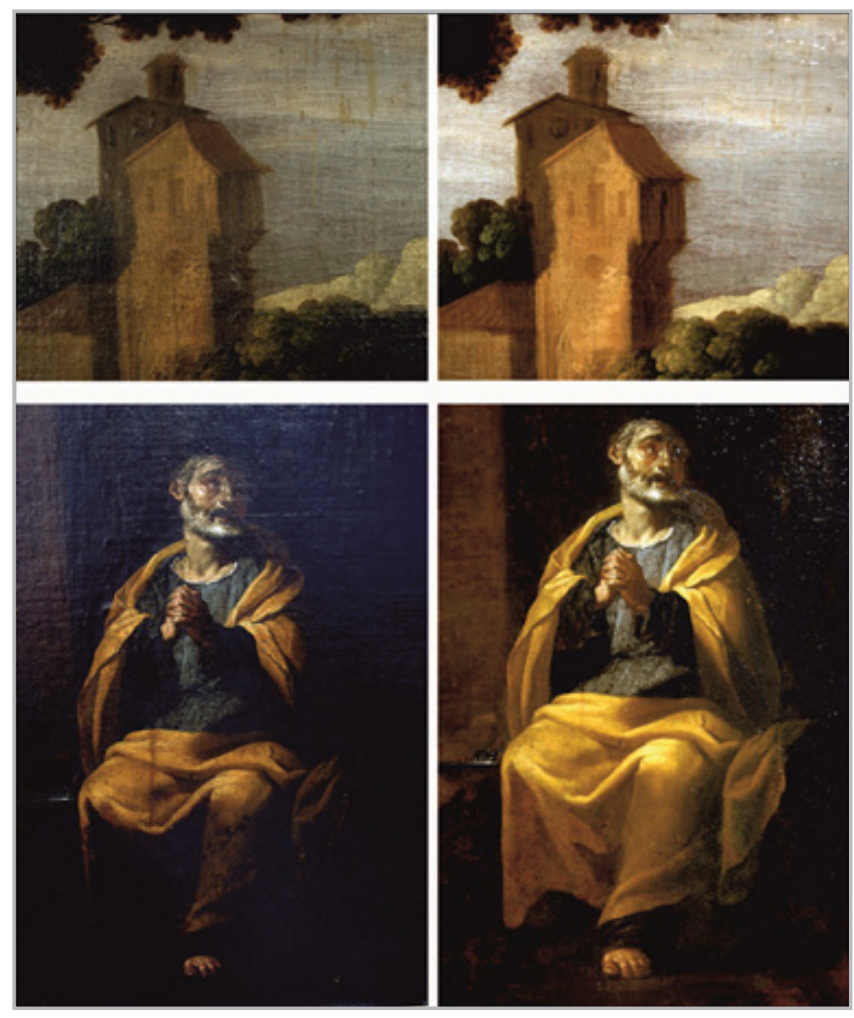

Figura 6.- Detalles de acabado: antes y después de la intervención.

\section{Metodología de análisis}

\section{Muestras}

El estudio que presentamos consistió en la toma de 5 muestras de material pictórico [tabla 1]: un microfragmento de pintura azul del cielo, otro de color marrón procedente de la zona de ramas de un árbol, otra procedente del ramaje (hojas superpuestas a un tejado), y otras dos procedentes directamente del ramaje (hojas). La elección de las zonas de muestreo se seleccionó en función de un examen visual y radiográfico previos. Se analizaron tanto los propios pigmentos como las preparaciones que los subyacen, un total de 95 análisis en SEM-EDX. La muestra SP08 se dedicó íntegramente para su caracterización orgánica por pirolisis analítica (Py-GC-MS).

\section{Técnicas de análisis}

Microscopía electrónica de barrido con espectroscopía de rayos $x(S E M-E D X)$

Es una técnica de imagen y de análisis espectroscópico a partir del bombardeo de la muestra con electrones. Los electrones retrodispersados por la muestra se recogen en un detector específico para producir una imagen muy aumentada cuyas tonalidades de grises están en función del número atómico de los elementos químicos presentes (más adelante, para describir diferentes áreas de las muestras analizadas en SEM, se hace referencia a estas gamas de grises que se corresponden con diferentes 
Tabla 1.- Muestras de pigmentos analizados. ID. UAR: código Unidade de Arqueometría.

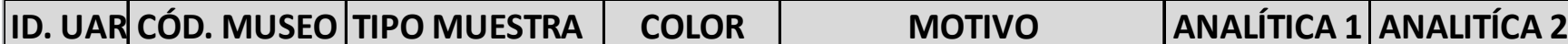

\begin{tabular}{|l|c|c|c|c|c|c|}
\hline SP01 & A & Esquirla pintura & Azul & Cielo & LUPA & SEM-EDX \\
\hline SP02 & B & Esquirla pintura & Marrón & Arbol (ramas) & LUPA & SEM-EDX \\
\hline SP03 & C & Esquirla pintura & Marrón & Ramaje (hojas) / Tejado & LUPA & SEM-EDX \\
\hline SP08 & C & Esquirla pintura & Marrón & Ramaje (hojas) & Py-GC-MS & - \\
\hline SP09 & C & Esquirla pintura & Marrón & Ramaje (hojas) & LUPA & SEM-EDX \\
\hline
\end{tabular}

composiciones y no con colores visibles). En el proceso de choque de los electrones también se generan rayos $X$ que son característicos de cada elemento químico, lo que permite su identificación y cuantificación. El equipo que se utilizó fue un EVO LS15 con microanálisis INCA incorporado. Las condiciones de medida fueron: $100 \mathrm{~s}$ para la adquisición de los espectros; 20,3 s para el escaneado de fotos; I probe de 1 a 1,8 nA, $20 \mathrm{kV}$ de voltaje y una distancia de trabajo (WD) de $8,5 \mathrm{~mm}$, presión variable y detección de electrones retrodispersados. Las muestras se depositaron sobre un porta, sin necesidad de aplicar tratamientos previos.

Pirolisis-Cromatografía de gases-Espectrometría de masas (Py-GC-MS y THM-GC-MS)

La Py-GC-MS, también conocido como pirolisis analítica convencional, produce la descomposición térmica, en ambiente inerte (gas helio), de sustancias macromoleculares (incluyendo polímeros) (Voorhees 2013). Los productos de pirolisis se separan mediante cromatografía de gases, y se identifican por sus espectros de masas. La Py-GC-MS es un método frecuentemente usado para el análisis de polímeros (naturales y sintéticos) de composición desconocida, donde se analiza la muestra en fase sólida sin tratamientos previos. El equipo está compuesto de tres componentes acoplados que consisten en un pirolizador CDS Pyroprobe 5000, un cromatógrafo de gases Agilent $6890 \mathrm{~N}$ y un detector de masas Agilent 5975. La muestra se introdujo en un tubo de cuarzo con lana de vidrio, a continuación, se introdujo el tubo en el pirolizador. La pirolisis se mantuvo a $650{ }^{\circ} \mathrm{C}$ durante 10 segundos. El cromatógrafo operó en modo split (1:10). El programa de temperatura del horno tuvo una Ta inicial de $60{ }^{\circ} \mathrm{C}$ y una final de $325^{\circ} \mathrm{C}$, con rampa de calentamiento a $20{ }^{\circ} \mathrm{C} / \mathrm{min}$. La columna cromatográfica fue una HP5MS. El espectrómetro cuadrupolo operó en modo de ionización por impacto de electrones (El) a $70 \mathrm{eV}$, escaneando masas en el rango $\mathrm{m} / \mathrm{z}$ de 50 a 500 (Kaal et al., 2014). Se ha estimado las proporciones relativas de los productos de pirolisis principales, tomando las áreas de los fragmentos $\mathrm{m} / \mathrm{z}$ característicos de cada compuesto y dividido por la suma de las áreas de todos los compuestos considerados. Se expresan las proporciones relativas como porcentaje del área total de los picos cuantificados (\% TQPA). En un segundo análisis de la muestra se realizó otra determinación, THM-GC-MS, también conocido como Py-TMAH-GC-MS (Van den Berg et al., 2000b). Esta segunda analítica difiere con la primera en que se realiza una preparación previa de la muestra (con hidróxido de tetrametilamonio, TMAH) que asegura la identificación de los compuestos polares como los ácidos grasos (y otros componentes que contengan grupos carboxílicos, que se descarboxilan en Py-GC-MS si no son previamente derivatizados). Con este método, se produce una hidrólisis y derivatización (metilación) simultánea, reacción que tiene un estímulo en forma de un pulso térmico. En este segundo análisis, anteriormente a la introducción de los tubos de cuarzo con la muestra, se añadió una alícuota de TMAH (Sigma-Aldrich, 25\% en agua) mediante una pipeta de vidrio. Se dejó la muestra en contacto con la disolución TMAH durante media hora para favorecer la derivación y se introdujo en el pirolizador para proceder a su análisis en las mismas condiciones que las aplicadas en la Py-GC-MS.

Los pigmentos se han caracterizado por medio del análisis elemental y los componentes orgánicos por técnicas cromatográficas. En ambos casos se ha utilizado la bibliografía especializada que se cita en el texto para la interpretación de los resultados.

\section{Resultados y discusión}

Análisis elemental del microfragmento de pintura azul del cielo SP01

Preparación. Las zonas homogéneas de la visualización de la imagen BSE (imagen SEM de electrones retrodispersados) tienen calcio, azufre y carbono, probablemente cristalizados como sulfatos y carbonatos de calcio, plomo, probablemente como carbonatos de plomo, y silicio, como silicatos [figura 7, tabla 2]. Las zonas granulosas tienen la misma composición pero con algo más de silicio y de hierro. Hay alguna zona oscura de similar composición pero enriquecida en carbono. Las otras zonas más claras de la preparación, son de la misma composición que las zonas homogéneas pero están más enriquecidas en plomo. En resumen, la preparación estaría formada por carbonatos de calcio (¿calcita?) y sulfatos de calcio (yeso) acompañados de tierras coloreadas formadas por silicatos y óxidos de hierro y sin descartar la inclusión de algún aglutinante orgánico. 


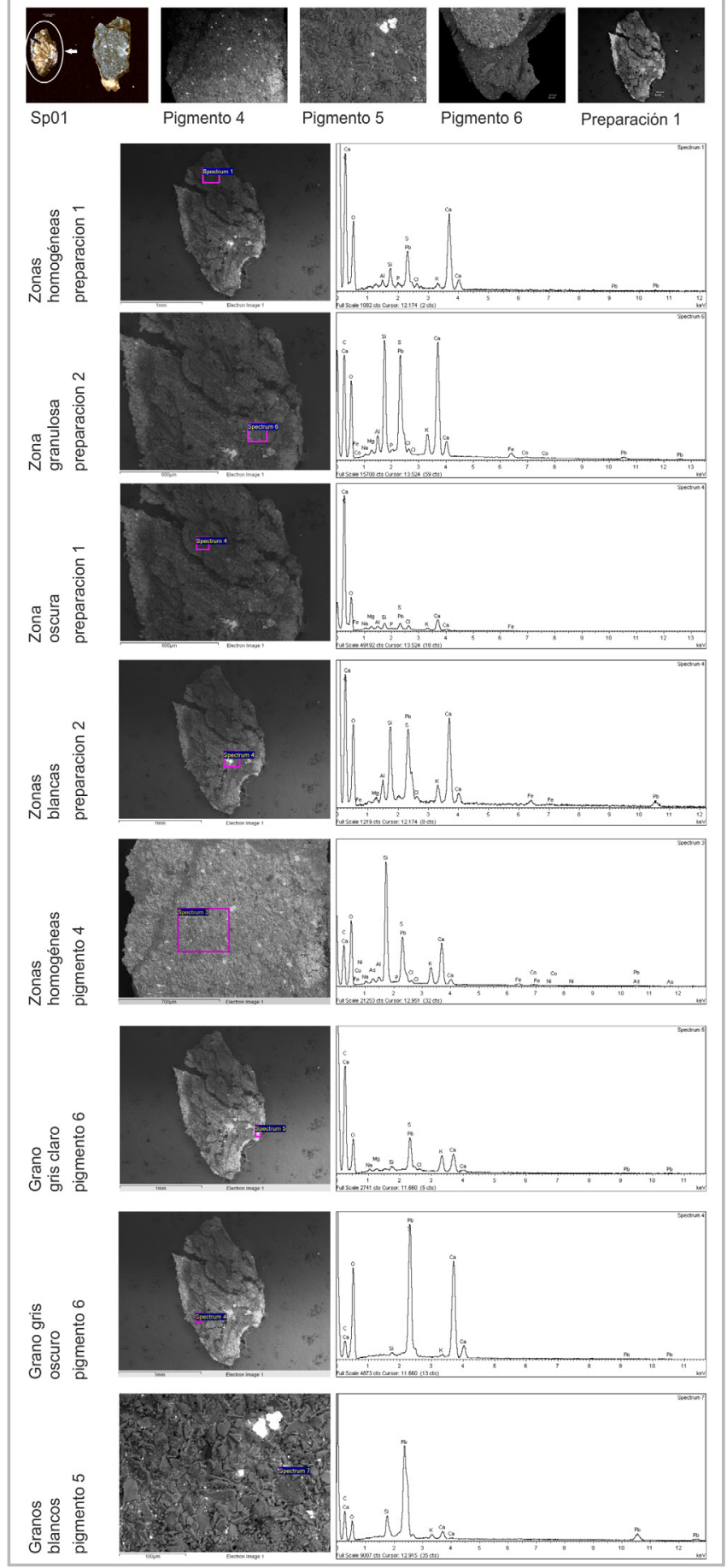

Figura 7.- Selección de imágenes SEM y espectros EDX del microfragmento azul del cielo SP01. En las imágenes SEM se indica el área analizada.

Pigmento. Las zonas homogéneas tienen calcio y azufre, probablemente como yeso, silicio abundante, potasio, cobalto, níquel y plomo (como carbonato de plomo). Los granos grises tienen la misma composición pero están más enriquecidos en silicio, potasio, cobalto y arsénico respecto al calcio y al plomo. El grano gris claro es similar a las zonas homogéneas descritas anteriormente pero con mucho más carbono y menos elementos químicos atribuibles al color. El grano gris oscuro es similar al grano gris claro pero más rico en yeso. Los granos blancos son básicamente carbonatos de plomo. El pigmento identificado es azul de esmalte, también llamado vidrio de cobalto, un pigmento muy utilizado entre los siglos XVI y XVIII. Se caracteriza por ser un vidrio de potasa con cobalto como mineral colorante y que puede degradarse hacia colores grises o pardos por pérdida del potasio, provocando así un cambio de coordinación de tetraédrica a octaédrica en el cobalto. El potasio lixiviado reacciona con los ácidos grasos del aceite aglutinante formando jabones (Robinet et al., 2011; Spring et al., 2005). El mineral del cual se obtuvo el cobalto podría haber sido erythrite/eritrina/flor de cobalto $\left(\mathrm{Co}_{3}\left(\mathrm{AsO}_{4}\right)_{2} \cdot 8 \mathrm{H}_{2} \mathrm{O}\right)$. El uso de este mineral justificaría la presencia de arsénico y además, al formar una serie continua con la annabergite $\left(\mathrm{Ni}_{3}\right.$ $\left.\left(\mathrm{AsO}_{4}\right)_{2} \cdot 8 \mathrm{H}_{2} \mathrm{O}\right)$, explicaría además la presencia del níquel, detectado en pequeñas cantidades. El azul de esmalte se usó históricamente mezclado con el blanco de plomo o incluso se ha citado como aplicado sobre capas blancas de plomo, con el objeto de que resalte y se aprecie bien el tono azul del pigmento (Doerner, 2011), de ahí que sea coherente la detección de plomo en el análisis.

Análisis elemental del microfragmento de pintura marrón del árbol (ramas) SPO2

Preparación. El granulado gris claro está compuesto básicamente de calcio (carbonato de calcio), carbono y plomo (carbonatos de plomo, blanco de plomo) [figura 8, tabla 2]. También se detectaron pequeñas cantidades de manganeso y hierro. El granulado gris oscuro de la base tiene una composición similar al anterior pero con mayor concentración de carbono. Los granos grises tienen una composición similar, si bien con más silicio (silicatos) y calcio, probablemente como carbonato. Los granos blancos tienen menos carbono y más hierro y manganeso, aunque el elemento que más incrementa su concentración es el plomo, probablemente como hidroxicarbonato de plomo (blanco de plomo). Destaca, en una muestra, la identificación ocasional de mercurio en una concentración del 21,7\%. Esta partícula, muy probablemente de bermellón (sulfuro de mercurio sintético, fabricado por los árabes desde el siglo VIII), debe de corresponderse con una contaminación de pigmento rojo de la paleta empleada que no debería de estar en la preparación. La convivencia de blanco de plomo con bermellón se desaconseja porque reaccionan en el caso de pinturas murales con alto grado de humedad (Doerner 2011; si bien, tomamos con cautela las aseveraciones de esta obra pues es un libro poco revisado). En la pintura al óleo esta mezcla es muy frecuente para conseguir rosados utilizando el blanco de plomo como diluyente del color. En todos los análisis de la submuestra preparación 3, se detecta cobre y arsénico (con silicio y potasio), correspondiéndose pues con pequeñas cantidades de azul de esmalte. Las fibras analizadas son básicamente orgánicas pero están relativamente impregnadas de material inorgánico, en especial plomo y calcio, tratándose seguramente de carbonatos de calcio y blanco de plomo. De modo general, podemos decir que predomina el carbonato de calcio en la preparación respecto al yeso. 


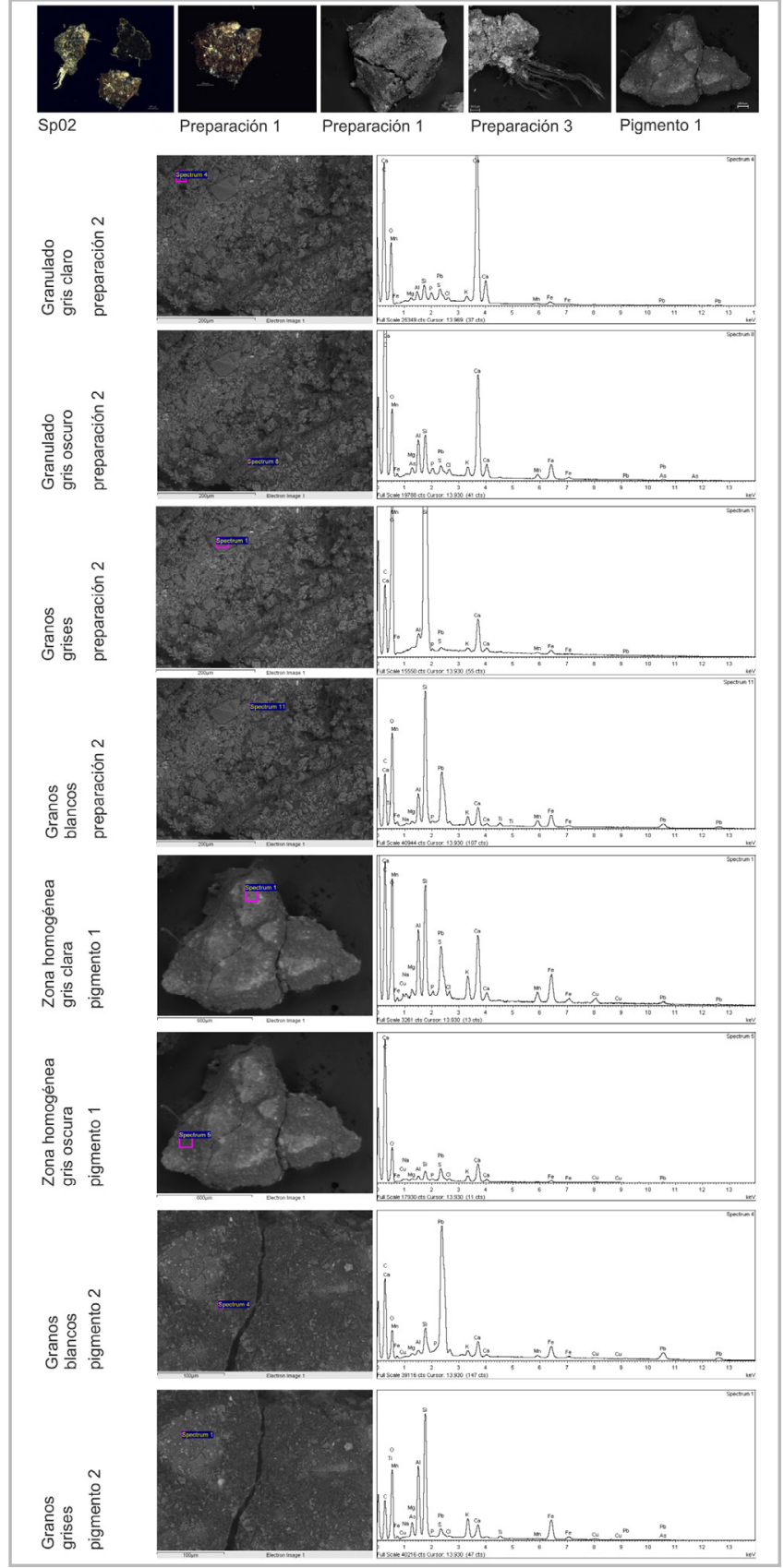

Figura 8.- Selección de imágenes SEM y espectros EDX del microfragmento pardo del árbol SP02. En las imágenes SEM se indica el área analizada.

Pigmento. Las zonas homogéneas gris claro tienen aluminio, silicio, azufre, calcio, hierro, manganeso, cobre y plomo. Estos elementos químicos podrían corresponderse con dos pigmentos, uno marrón a base de óxidos de manganeso y hierro -denominado sombra- y otro verde con base de cobre. El plomo podría tener su origen en el blanco de plomo. Las zonas homogéneas gris oscuro de la pintura tienen la misma composición que las anteriores pero son menos ricas en hierro y el manganeso a veces no se detecta; el nivel de plomo es algo menor y hay una mayor concentración de carbono. Los granos grises de la pintura tienen una composición parecida, pero con detección adicional de otros elementos químicos (silicio, cobalto, níquel y arsénico) que se pueden atribuir al pigmento azul (azul de esmalte) descrito en SP01. Los granos blancos son una mezcla de calcio (carbonatos de calcio) hierro (óxidos de hierro), cobre (veladuras de cobre, hechas probablemente con verdigrís, y plomo (probablemente como blanco de plomo). Destaca especialmente la presencia de bario en un análisis, que debe de tener su origen como sulfato de bario (se detecta un 5,2\% de azufre) procedente de algún repinte. En resumen, el pigmento de este microfragmento no sería un único pigmento si no una mezcla de 3-4 pigmentos: blanco de plomo, óxidos de hierro y manganeso marrones (sombra), un pigmento con base en cobre, y pequeñas cantidades de pigmento azul. El área de extracción del mismo sería pues una zona marrón original de la corteza del árbol muy próxima a una zona de hojas (y quizás de cielo).

Análisis elemental del microfragmento de pintura marrón del ramaje (hojas)/tejado SPO3

Preparación. Las zonas homogéneas están compuestas básicamente por calcio, probablemente carbonato de calcio, con pequeñas contribuciones de silicio, aluminio y plomo (tierras y blanco de plomo) [figura 9, tabla 2].

Pigmento. Las zonas homogéneas muestran que hay un predominio de compuestos orgánicos -mucho carbonoy hierro en bajas concentraciones. El pigmento estaría básicamente compuesto por óxidos de hierro con un aglutinante orgánico. Inicialmente se recogió esta muestra pensando que se trataba de una veladura verde degradada pero al no detectar cobre debemos decantarnos por un pigmento originalmente marrón aplicado al tejado. y que podría ser marrón de óxido de hierro (conocidos clásicamente en el mercado como marrón de Prusia o de Berlín; Doerner, 2011). Descartamos la aplicación de una sombra, ya que esta está compuesta por material rico en hierro con presencia de silicio (silicatos) y manganeso, y estos dos últimos elementos no han sido detectados en este análisis.

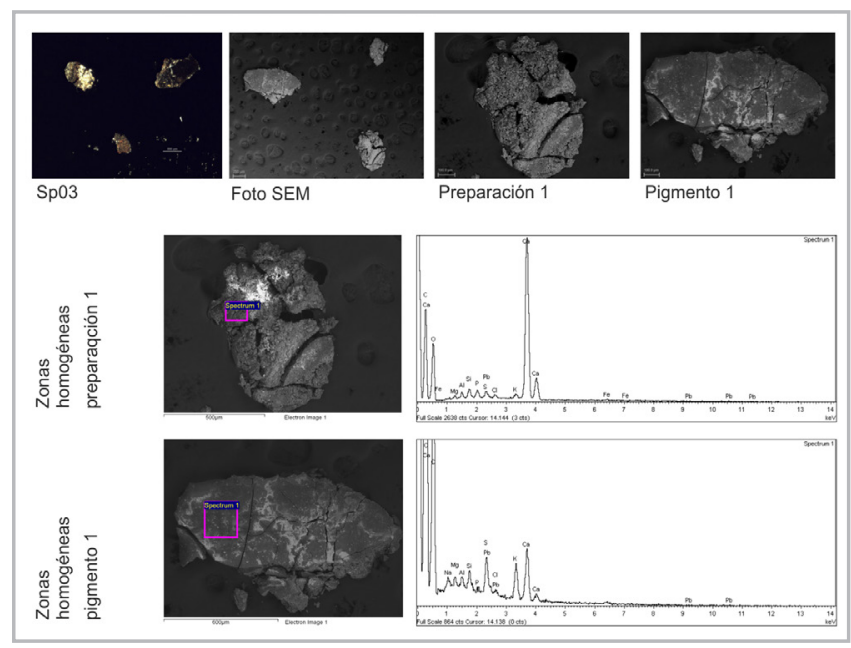

Figura 9.- Selección de imágenes SEM y espectros EDX del microfragmento marrón SP03. En las imágenes SEM se indica el área analizada. 
Análisis elemental del microfragmento de pintura marrón del ramaje (hojas) SPO9

Preparación. Está compuesta básicamente por calcio, probable carbonato, junto con otros elementos como hierro, silicio y una alta concentración de carbono orgánico [figura 10, tabla 2]. Un punto brillante que se analizó en la base está formado por silicio, cobre, arsénico y plomo. Podría tratarse de veladura de cobre junto con otras impurezas de tierras y blanco de plomo. Las zonas con cristales son unos depósitos granulares localizados sobre el pigmento y que se aprecian únicamente en la imagen BSE. Están compuestos de calcio y de azufre, por lo que debe de tratarse de eflorescencias procedentes de la recristalización del yeso utilizado en alguna restauración antigua.

Pigmento. La zona homogénea del área $\mathrm{A} 1$ (A2, misma

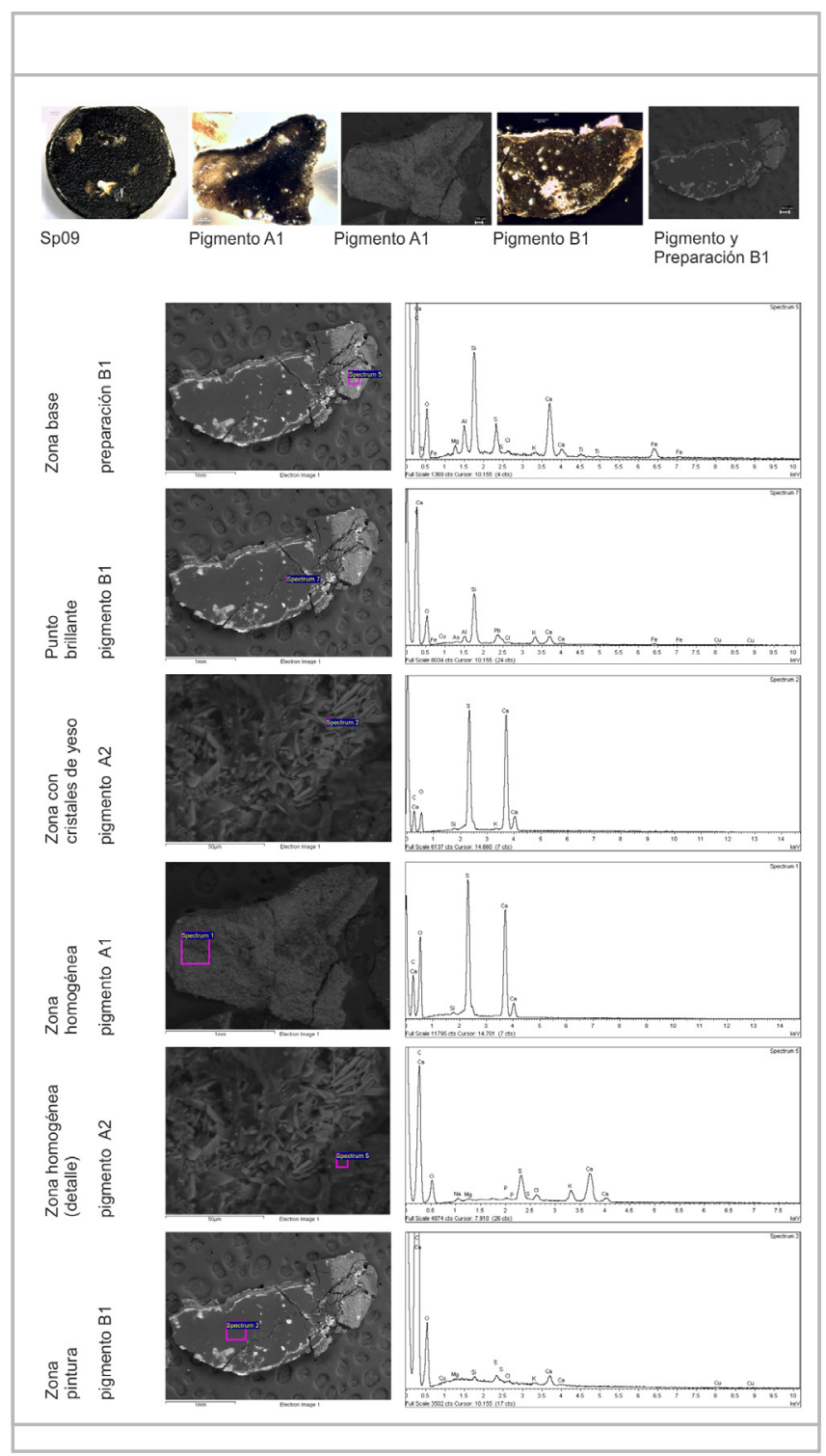

Figura 10.- Selección de imágenes SEM y espectros EDX del microfragmento marrón SP09. En las imágenes SEM se indica el área analizada. área en detalle) tienen una composición muy rica en azufre y calcio (sulfatos de calcio y quizás carbonatos) y con bastante carbono (carbonatos y material orgánico). Esta composición confirmaría que esta área que se consideró pigmento realmente era preparación quizás cubierta de barniz, o tampoco se puede descartar que se trate de un pigmento orgánico (laca) mezclado con una carga inerte. En el área B1 se detecta cobre como responsable del color $(0,3-0,4 \%)$ y con una concentración muy elevada de carbono (70-78\%). Estos datos apuntan a que podría tratarse de una veladura de cobre. En algún análisis se detectan pequeñas cantidades de cloro, que sería igualmente compatible con la presencia de una veladura de cobre, por estar relacionado con el método de manufactura del verdigrís según se refleja en otros estudios (Acroyd et al., 2000; Kühn 1993; Sancho et al. ,2004; Sancho Cubino 2004; Santos Gómez et al., 2002, 2003; Van den Berg et al., 2000a).

Tabla 2- . Síntesis de la composición elemental de las muestras analizadas en SEM-EDX. SP: con *, espectros de análisis incluidos en las figuras 7-10. Las clasificaciones de zonas homogéneas, granulosas, puntos brillantes, zonas oscuras, blancas, grises... hacen referencia a heterogeneidades texturales y composicionales que se detectan en las imágenes BSE (imagen SEM de electrones retrodispersados) pero que no se distinguen a un nivel macroscópico en las imágenes ópticas.

\begin{tabular}{|c|c|c|c|}
\hline DESCRIPCIÓN & ÁREA ANÁLISIS EDX & ELEMENTOS MAYORITARIOS & SP \\
\hline \multicolumn{3}{|c|}{ Preparación del microfragmento de pintura azul del cielo SP01 } & \\
\hline Zonas homogéneas & Preparación 1 & (Si) (S) $\mathrm{Ca} \mathrm{Pb}$ & * \\
\hline Zonas homogéneas & Preparación 2 & $\mathrm{Si}(\mathrm{S}) \mathrm{Ca} \mathrm{Pb}$ & \\
\hline Zona granulosa & Preparación 2 & $\mathrm{Si} \mathrm{S} \mathrm{Ca} \mathrm{Fe} \mathrm{Pb}$ & * \\
\hline Zona oscura & Preparación 2 & $\mathrm{C} \mathrm{S} \mathrm{Ca}$ & * \\
\hline Zonas blancas & Preparación 1 & $\mathrm{SiS} \mathrm{Ca} \mathrm{Fe} \mathrm{Pb}$ & * \\
\hline Zona blanca & Preparación 2 & $\mathrm{Si} \mathrm{S} \mathrm{Ca} \mathrm{Fe} \mathrm{Pb}$ & \\
\hline \multicolumn{4}{|c|}{ Pigmento del microfragmento de pintura azul del cielo SP01 } \\
\hline Zonas homogéneas & Pigmento 4 & $\mathrm{Si} \mathrm{S} \mathrm{K} \mathrm{Ca} \mathrm{Co} \mathrm{Ni} \mathrm{As} \mathrm{Pb}$ & * \\
\hline Zona homogénea & Pigmento 5b & $\mathrm{Si} \mathrm{S} \mathrm{K} \mathrm{Ca} \mathrm{Co} \mathrm{Ni} \mathrm{As} \mathrm{Pb}$ & \\
\hline Zonas homogéneas & Pigmento 6 & $\mathrm{~S} \mathrm{Ca}$ & \\
\hline Granos grises & Pigmento 5 & Si K Co Ni As $(\mathrm{Zn})$ & * \\
\hline Grano gris claro & Pigmento 6 & $\mathrm{CSCa}$ & \\
\hline Grano gris oscuro & Pigmento 6 & $\mathrm{SCa}$ & * \\
\hline Granos blancos & Pigmento 5 & $\mathrm{~Pb}$ & * \\
\hline \multicolumn{4}{|c|}{ Preparación del microfragmento de pintura marrón del árbol (ramas) SP02 } \\
\hline Granulado gris claro & Preparación 2 & $\mathrm{Ca} \mathrm{Mn} \mathrm{Fe} \mathrm{Pb}$ & * \\
\hline Granulado gris claro & Preparación 3 & $\mathrm{Cu} \mathrm{As} \mathbf{P b}$ & \\
\hline Granulado gris oscuro & Preparación 2 & $\mathrm{Ca} \mathrm{Mn} \mathrm{Fe} \mathrm{Pb}$ & * \\
\hline Granulado gris oscuro & Preparación 3 & $\mathrm{Ca} \mathrm{Fe} \mathrm{Cu} \mathrm{As} \mathbf{P b}$ & \\
\hline Granos grises & Preparación 2 & $\mathrm{Si} / \mathrm{Ca}(\mathrm{Fe})$ & * \\
\hline Granos blancos & Preparación 2 & $\mathrm{Al} \mathrm{Si} \mathrm{Ca} \mathrm{Ti} \mathrm{Mn} \mathrm{Fe} \mathbf{H g} \mathrm{Pb}$ & * \\
\hline Grano blanco & Preparación 3 & $\mathrm{Cu} \mathrm{As} \mathrm{Pb}$ & \\
\hline Fibra & Preparación 3 & $\mathrm{C} \mathrm{Ca}(\mathrm{Pb})$ & \\
\hline Fibra & Preparación 4 & $\mathrm{C} \mathrm{Ca}(\mathrm{Pb})(\mathrm{As})$ & \\
\hline Fibra con costra & Preparación 4 & $\mathrm{C} \mathrm{Ca}(\mathrm{Pb})(\mathrm{As})$ & \\
\hline \multicolumn{4}{|c|}{ Pigmento del microfragmento de pintura marrón del árbol (ramas) SPO2 } \\
\hline Zona homogénea gris clara & Pigmento 1 & $\mathrm{Al} \mathrm{Si} \mathrm{S} \mathrm{Ca} \mathrm{Fe} \mathrm{Mn} \mathrm{Cu} \mathrm{Pb}$ & * \\
\hline Zona homogénea gris oscura & Pigmento 1 & $\mathrm{C} \mathrm{Ca} \mathrm{Fe}(\mathrm{Mn}) \mathrm{Cu}$ & * \\
\hline Zona homogénea gris oscura & Pigmento 2 & $\mathrm{C} \mathrm{Ca} \mathrm{Fe} \mathrm{Cu}(\mathrm{Co})(\mathrm{Ni})$ & \\
\hline Granos blancos & Pigmento 2 & $\mathrm{Ca} \mathrm{Fe} \mathrm{CuBa}$ & * \\
\hline Granos grises & Pigmento 2 & $\mathrm{C} \mathrm{Ca} \mathrm{Fe} \mathrm{Cu}$ & * \\
\hline \multicolumn{4}{|c|}{ Preparación del microfragmento de pintura marrón del ramaje (bojas)/tejado $\mathrm{SPO} 3$} \\
\hline Zonas homogéneas & Preparación 1 & $\mathrm{CaFe}$ & * \\
\hline Zona cargada & Preparación 1 & C Ca Fe & \\
\hline \multicolumn{4}{|c|}{ Pigmento del Microfragmento de pintura marrón del ramaje (bojas)/tejado SPO3 } \\
\hline Zonas homogéneas & Pigmento 1 & C (Ca) Fe & $*$ \\
\hline \multicolumn{4}{|c|}{ Preparación del microfragmento de pintura marrón del ramaje (bojas) SP09 } \\
\hline Zona base & Preparación (área B1) & $\mathrm{CCaFe}$ & * \\
\hline \multicolumn{4}{|c|}{ Pigmento del microfragmento de pintura marrón del ramaje (bojas) SP09 } \\
\hline Punto brillante & Pigmento (área B1) & $\mathrm{Si} \mathrm{Cu} \mathrm{As} \mathrm{Pb}$ & * \\
\hline Zona con cristales de yeso & Pigmento (área A2) & $\mathrm{S} \mathrm{Ca}$ & * \\
\hline Zona homogénea & Pigmento (área $\mathrm{A} 1$ ) & $\mathrm{CsCa}$ & * \\
\hline Zona homogénea (detale) & Pigmento (área A2) & C S Ca & * \\
\hline Zona homogénea & Pigmento (área B1) & $\mathrm{CCu}$ & * \\
\hline
\end{tabular}


Tabla 3- . Listado de los compuestos de pirolisis Py-GC-MS de SP08. (TR tiempos de retención; m/z: relación masa/carga, \% TQPA: proporciones relativas; Der.: derivado).

\begin{tabular}{|c|c|c|c|c|c|c|c|}
\hline Compuesto & TR (min) & $m / z$ & $\%$ TQPA & Compuesto & TR (min) & $m / z$ & $\%$ TQPA \\
\hline Tolueno & 2,064 & $91+92$ & 9,92 & Alcano $\mathrm{C}_{18}$ & 12,685 & $57+71$ & 0,06 \\
\hline $\mathrm{C}_{2}$-benzene & 2,744 & $91+106$ & 4,94 & Alcano $\mathrm{C}_{20}$ & 13,381 & $57+71$ & 0,04 \\
\hline Der. monómero & 3,455 & $67(81)$ & 1,89 & Alqueno $\mathrm{C}_{8}$ & 4,334 & $55+69$ & 1,27 \\
\hline No identificado & 3,73 & $55+68(112)$ & 3,60 & Alqueno $\mathrm{C}_{9}$ & 5,032 & $55+69$ & 1,27 \\
\hline o-cymeno (monómero) & 3,829 & $119+134$ & 0,43 & Alqueno $\mathrm{C}_{10}$ & 5,757 & $55+69$ & 0,78 \\
\hline m-cymeno (monómero) & 4,13 & $119+134$ & 0,19 & Alqueno $\mathrm{C}_{11}$ & 6,412 & $55+69$ & 1,15 \\
\hline Der. monómero & 4,564 & $119+148(91)$ & 0,07 & Alqueno $\mathrm{C}_{12}$ & 7,045 & $55+69$ & 0,96 \\
\hline p-cymeno (monómero) & 4,638 & $119+134$ & 0,17 & Alqueno $\mathrm{C}_{13}$ & 7,626 & $55+69$ & 0,54 \\
\hline Der. dímero & 7,191 & $111+192$ & 0,18 & Alqueno $\mathrm{C}_{14}$ & 8,208 & $55+69$ & 0,45 \\
\hline Der. dímero & 7,455 & $111+192$ & 1,04 & Ácido graso $\mathrm{C}_{4}$ & 3,071 & $60+73$ & 0,75 \\
\hline Der. dímero & 7,856 & $107+188$ & 0,93 & Ácido graso $\mathrm{C}_{5}$ & 3,704 & $60+73$ & 1,44 \\
\hline Der. trímero & 10,294 & $192+304$ & 0,05 & Ácido graso $\mathrm{C}_{6}$ & 4,264 & $60+73$ & 3,54 \\
\hline Der. trímero & 10,445 & $192+304$ & 0,40 & Ácido graso $\mathrm{C}_{7}$ & 4,871 & $60+73$ & 3,66 \\
\hline Der. trímero & 10,886 & $192+304$ & 0,11 & Ácido graso $\mathrm{C}_{8}$ & 5,489 & $60+73$ & 5,15 \\
\hline Ácido dehidroabiético (1) & 9,936 & $197+239+254$ & 0,32 & Ácido graso $\mathrm{C}_{9}$ & 6,184 & $60+73$ & 2,69 \\
\hline Ácido dehidroabiético (2) & 10,024 & $141+239+254$ & 0,27 & Ácido graso $C_{10}$ & 6,933 & $60+73$ & 0,79 \\
\hline Alcano $\mathrm{C}_{7}$ & 3,548 & $57+71$ & 0,86 & Ácido graso $C_{11}$ & 7,455 & $60+73$ & 0,41 \\
\hline Alcano $\mathrm{C}_{8}$ & 4,311 & $57+71$ & 1,27 & Ácido graso $\mathrm{C}_{12}$ & 7,932 & $60+73$ & 0,42 \\
\hline Alcano $\mathrm{C}_{9}$ & 5,002 & $57+71$ & 1,06 & Ácido graso $C_{13}$ & 8,467 & $60+73$ & 0,37 \\
\hline Alcano $\mathrm{C}_{10}$ & 5,79 & $57+71$ & 1,15 & Ácido graso $\mathrm{C}_{14}$ & 8,919 & $60+73$ & 0,97 \\
\hline Alcano $C_{11}$ & 6,456 & $57+71$ & 0,85 & Ácido graso $C_{15}$ & 9,411 & $60+73$ & 0,45 \\
\hline Alcano $\mathrm{C}_{12}$ & 7,087 & $57+71$ & 2,31 & Ácido graso $\mathrm{C}_{16}$ & 9,863 & $60+73$ & 32,91 \\
\hline Alcano $\mathrm{C}_{13}$ & 7,676 & $57+71$ & 0,67 & Ácido graso $\mathrm{C}_{18}$ & 10,729 & $60+73$ & 4,96 \\
\hline Alcano $\mathrm{C}_{14}$ & 8,244 & $57+71$ & 1,06 & Ácido graso $\mathrm{C}_{16}$ (metil éster) & 9,458 & $74+87$ & 0,45 \\
\hline Alcano $\mathrm{C}_{15}$ & 11,523 & $57+71$ & 0,23 & Ácido graso $\mathrm{C}_{18}$ (metil éster) & 10,408 & $74+87$ & 0,40 \\
\hline Alcano $\mathrm{C}_{16}$ & 11,928 & $57+71$ & 0,09 & & \multirow{2}{*}{\multicolumn{2}{|c|}{ total }} & \multirow[b]{2}{*}{100,00} \\
\hline Alcano $\mathrm{C}_{17}$ & 12,317 & $57+71$ & 0,06 & & & & \\
\hline Resumen principales compuestos & & & & & & & $\%$ TQPA \\
\hline Ácidos grasos & & & & & & & 58,50 \\
\hline Ácidos grasos (ésteres) & & & & & & & 0,85 \\
\hline Alcanos/alquenos & & & & & & & 16,13 \\
\hline Resina cetónica: monómeros & & & & & & & 2,76 \\
\hline Resina cetónica: dímeros & & & & & & & 2,14 \\
\hline Resina cetónica: trímeros & & & & & & & 0,56 \\
\hline Resina natural & & & & & & & 0,59 \\
\hline Otros & & & & & & & 18,46 \\
\hline
\end{tabular}

Análisis Py-GC-MS del microfragmento de pintura marrón del ramaje (hojas) SP08

Se detectan, aunque en muy baja proporción (un 5\% de TQPA) los mismos productos de la resina cetónica en la pintura que los que han sido encontrados en otra muestra de barniz utilizado en la restauración (SM2A, barniz de retoque de Talens aplicado en una fase anterior de restauración) [Tabla 3]. Además, se detectaron una serie de compuestos alifáticos: ácidos grasos $\left(\mathrm{C}_{4}-\mathrm{C}_{18}\right)$, procedentes de los aceites de la pintura, y $n$-alcanos $\left(C_{7}-\right.$ $\left.C_{20}\right)$ y $n$-alquenos $\left(C_{8}-C_{18}\right)$, probablemente procedentes principalmente de la degradación por descarboxilación de los ácidos grasos durante la pirólisis. Estos ácidos grasos 
indicarían la presencia de lípidos -generalmente aceites secantes- empleados como aglutinantes (Colombini et al. 2001). En esta misma línea, la presencia de metil ésteres de ácido palmítico y ácido esteárico, evidencia un proceso de polimerización de los aceites (ya que este análisis no incluye la derivación de grupos carboxílicos; Erhardt, 1998). Este proceso de polimerización es el que permite que se forme una matriz que engloba de forma estable las partículas del pigmento haciendo así su función como aglutinante. De haber aplicado GC-MS con los aceites derivados se podría afinar en la identificación del aceite a través de la proporción de ácidos grasos (Mills \& White, 1987), pero a través de la técnica de Py-GC-MS los ácidos grasos solo se detectan como ésteres si están esterificados. La detección de ácido abiético indica la presencia de una resina diterpénica natural, de la familia de las coníferas Pinaceae (pino, pícea, alerce) que se encuentra en baja proporción $(0,6 \%)$ posiblemente por procesos de degradación. La ausencia de marcadores de monómeros de trementina, como los pinenos y los carenos, sugieren que los ácidos abiéticos proceden de una sustancia tipo resina de colofonia.

\section{Análisis THM-GC-MS del microfragmento de pintura marrón del ramaje (hojas) SP08}

Los compuestos identificados por esta técnica son el ácido graso $\mathrm{C}_{16}$ (ácido palmítico) y $\mathrm{C}_{18}$ (ácido esteárico), ahora sí detectado como ésteres a través de la derivación (metilación) con TMAH [tabla 4]. La presencia, y abundancia, del diácido graso $\mathrm{C}_{9}$ (ácido acelaico, detectado como dimetil ester) podría confirmar el mal estado de preservación de los aceites en la muestra de pintura según indican Mills y White (1987), si bien puede deberse simplemente a un fenómeno paralelo a la polimerización. La relación entreácido subérico $\left(\mathrm{C}_{8}\right.$ diácido) yácido acelaico es 0,13 y la relación entre ácido sebácico $\left(C_{10}\right.$ diácido) y ácido acelaico es 0,03 . Estas relaciones reflejan el grado de transposición de doble enlace, que suele incrementar durante la polimerización de los aceites, principalmente como resultado del envejecimiento (Lazzari y Chiantore, 1999; Van den Berg et al., 2002; Bonaduce et al., 2012). El ácido oleico $\left(C_{18: 1}\right)$ tiene una presencia de solo 1,3\%,I Sería esperable una proporción elevada de ácidos grasos nosaturados pero hay que tener en cuenta que estos ácidos grasos "desaparecen" al polimerizar. También se detectan una serie de dímeros de la resina sintética (retoque de Talens), y marcadores de ácidos grasos con hidroxilación -convertido en grupos metoxílicos por la derivatización-, en posiciones en el medio de la cadena (metil ésteres de ácidos grasos con substituciones: 9,10-dimetoxi- $C_{16}$; 10,16-dimetoxi- $C_{16}$ y 9,10,18-trimetoxi- $C_{18}$ ). Estos ácidos grasos con hidroxilación son productos conocidos del biopolímero cutina (Nierop y Verstraten, 2004; Kolattukudy, 2001). La cutina está presente en las capas epicuticulares de hojas de plantas, y por lo tanto puede reflejar el uso de material vegetal en la producción del pigmento.
Tabla 4- . Listado de los compuestos de pirólisis THM-GC-MS de SP08. (TR tiempos de retención; $m / z$ : relación masa/carga, $\%$ TQPA: proporciones relativas; Der.: derivado).

\begin{tabular}{|c|c|c|c|}
\hline Compuesto & TR(min) & $\mathrm{m} / \mathrm{z}$ & $\%$ TQPA \\
\hline Diácido graso $\mathrm{C}_{7}$ (dimetil éster) & 6,223 & $55+59$ & 0,43 \\
\hline Díácido graso $\mathrm{C}_{8}$ (dimetil éster) & 6,920 & $55+59$ & 1,35 \\
\hline Benceno diacarboxilico (dimetil éster) & 7,007 & 163 & 0,44 \\
\hline Der. dímero & 7,147 & $111+192$ & 0,02 \\
\hline Díácido graso $\mathrm{C}_{9}$ (dimetil éster) & 7,411 & $55+59(152+185)$ & 10,52 \\
\hline Der. dímero & 7,437 & $111+192$ & 1,47 \\
\hline Díácido graso $\mathrm{C}_{10}$ (dimetil éster) & 8,019 & $55+59$ & 0,25 \\
\hline Ácido graso $C_{14}$ (metil éster) & 8,340 & $74+87$ & 0,48 \\
\hline Der. dímero & 8,631 & $98+112(192)$ & 0,12 \\
\hline Ácido graso $\mathrm{C}_{16}$ (metil éster) & 9,408 & $74+87$ & 46,56 \\
\hline Ácido graso $\mathrm{C}_{18: 1}$ (metil éster) & 10,213 & $55+69$ & 1,32 \\
\hline Ácido graso $\mathrm{C}_{18}$ (metil éster) & 10,353 & $74+87$ & 31,48 \\
\hline Der. trímero & 10,504 & $192+304$ & 0,03 \\
\hline Der. trímero & 10,659 & $192+304$ & 0,03 \\
\hline Der. trímero & 11,111 & $192+304$ & 0,02 \\
\hline Ácido graso $\mathrm{C}_{20}$ (metil éster) & 11,194 & $74+87$ & 0,38 \\
\hline Der. Cutina & 11,324 & $69+71+83+201$ & 1,76 \\
\hline Ácido dehidroabiético (metil ester) & 11,370 & $239+314$ & 0,79 \\
\hline 7-oxo-dehidroabietato (der. dimetilado) & 11,822 & $267+342$ & 0,68 \\
\hline No identificado & 11,822 & $267+342(283,227)$ & 0,68 \\
\hline Ácido graso $C_{22}$ (metil éster) & 11,988 & $74+87$ & 0,29 \\
\hline Der. Cutina & 12,216 & $71+81(201)$ & 0,70 \\
\hline \multirow[t]{2}{*}{ Acido graso $\mathrm{C}_{24}$ (metil éster) } & 12,730 & $74+87$ & 0,22 \\
\hline & total & & 100,02 \\
\hline Resumen principales compuestos & & & $\%$ TQPA \\
\hline Dímero resina cetónica & & & 1,61 \\
\hline Trímero resina cetónica & & & 0,08 \\
\hline Ácidos grasos & & & 80,72 \\
\hline Diácidos grasos & & & 12,55 \\
\hline Cutina & & & 2,45 \\
\hline Resina natural & & & 1,47 \\
\hline Otros & & & 1,12 \\
\hline total & & & 100,00 \\
\hline
\end{tabular}

Finalmente, se han detectado dos productos conocidos de resinas naturales: diterpenos de coníferas en base de ácido dehidroabiético (DHA): ácido dehidroabiético metil ester y 7-oxo-dehidroabietato. La abundancia del variante 7-oxoDHA se interpreta como un indicador de degradación (envejecimiento) de la resina diterpénica (Colombini et al, 2001; Van den Berg et al., 2000). Aunque la abundancia de estos compuestos es solo de 1,5\% por su mala preservación, en la resina DHA podría haber sido mucho más abundante en el momento de su aplicación. El uso de estas resinas en material de pintura es frecuente y los ácidos abiéticos han sido considerados como productos diagnósticos del resinato de cobre (Colombini et al., 2001; Eastaugh et al., 2008), pero en la luz del debate sobre la aplicación original de resinato o su formación por degradación a través de otra veladura de cobre (Van den Berg et al., 2000a), no se puede especificar el tipo de veladura concreto aplicado por el artista.

\section{Conclusiones}

El pigmento del microfragmento de pintura azul del cielo SP01 es azul de esmalte, un vidrio de potasa que tiene cobalto como mineral colorante y pequeñas impurezas naturales de arsénico y níquel. Probablemente el mineral 
con el que se elaboró el vidrio fuese un arseniato de cobalto llamado eritrina.

El pigmento del microfragmento de pintura marrón del árbol (ramas) SP02 es básicamente sombra -óxidos de hierro y manganeso- pero está mezclado con otros pigmentos como azul de esmalte, pequeñas cantidades de blanco de plomo. Este compuesto lo mezcla el pintor para obtener tonos claros y es ordinariamente el pigmento más abundante de la paleta tradicional. También hay presencia de cobre, probablemente formando parte de una veladura de cobre. Destacamos la identificación de una partícula de bermellón que podría proceder de una mezcla intencionada para lograr una tonalidad, aunque su baja concentración inclina a pensar más en una contaminación de la paleta del pintor.

El pigmento del microfragmento de pintura marrón del ramaje (hojas)/tejado SP03 está compuesto por óxidos de hierro y tiene un alto contenido en materia orgánica. Inicialmente se muestreó como posible pigmento verde degradado a marrón pero su composición apunta a que puede tratarse de un marrón original aplicado al tejado.

El pigmento del microfragmento de pintura marrón del ramaje (hojas) SP08 y SP09 confirma la presencia de cobre, que podría ser componente de una veladura de cobre. El análisis orgánico por pirólisis indica que el pigmento claramente tiene trazas de una resina cetónica, un barniz del siglo XX utilizado en alguna fase de restauración y también ácido abiético y su variante 7-oxodehidroabiético que son claramente indicadores de una resina natural del tipo colofonia, además de otros compuestos que confirmarían la presencia de cutina como restos vegetales. Debido a la inequívoca identificación de la resina se podría considerar el pigmento como un resinato de cobre, si bien la resina podría proceder también de restos de un barniz antiguo, que no tiene por que ser el original. El resinato de cobre se ha identificado históricamente como un material pictórico incorporado por el artista (Eastaugh et al., 2008), aunque hoy en día (Van den Berg et al., 2000; Colomina y Guerola, 2011-2012) se interpreta como una reacción de la veladura original por reacción con las resinas de los barnices, que desafortunadamente, tiene una tendencia a degradarse a tonos marronáceos. El conjunto de resultados nos lleva a pensar que el pigmento original para los tonos verdes podría haber sido un verdigrís con una veladura final en ciertos puntos.

En relación a la preparación de la pintura podemos decir que no es muy uniforme y que está formada por carbonatos de calcio y yeso en diferente concentración. En la preparación de SP01, SP08 y SP09 predomina el yeso, mientras que en la preparación de SP02 y SP03 fundamentalmente hay carbonato de calcio con presencia de silicatos y en parte óxidos de hierro. En SP02 además se detectan pequeñas concentraciones de blanco de barita. Todos estos compuestos son esperables como bases de pigmentos en pintura al óleo.
En cuanto al proceso de restauración, se ha logrado devolver parte del equilibrio cromático perdido, corregir deformaciones en el soporte gracias a la correcta tensión la sustitución del viejo bastidor y recuperar el reverso original oculto tras un tratamiento innecesario de reentelado. La realización de análisis químicos a pequeñas muestras de pintura tomadas en distintos puntos de la obra han permitido constatar que el pardeamiento de los verdes de árboles y follaje se deben a la presencia de veladuras verdes alteradas de cobre (quizás transformadas posiblemente a resinatos de cobre), y este hallazgo ha marcado el límite que la limpieza químico-mecánica de la capa pictórica debía respetar, es decir, se establece como criterio de restauración el mantenimiento de la veladura original oscurecida.

En definitiva, el análisis de los pigmentos y las preparaciones ha permitido identificar su naturaleza, azul de esmalte, sombras, óxidos de hierro, veladuras de cobre, blanco de plomo, carbonatos de calcio y yeso, compatibles con la época a la que pertenece. También ha servido para evaluar su estado de conservación, lo que ha ayudado a orientar las estrategias a seguir en el proceso de restauración de la obra. De este modo se pone de manifiesto la importancia que el conocimiento de los materiales constitutivos de las obras a través de las diferentes técnicas de análisis tiene para el diseño de los tratamientos de restauración y en definitiva para ahondar en el conocimiento de la naturaleza de las obras de arte.

En lo referente a esta obra, el próximo estudio que estamos elaborando es el análisis iconográfico que ha revelado el estudio radiográfico. Esto contribuirá sin duda, a un mayor entendimiento de la obra y a un mayor conocimiento del propio autor.

\section{Bibliografía}

ANGULO ÍNIIGUEZ, D. Y PÉREZ SÁNCHEZ, A.E. (1983): Historia de la pintura española: escuela madrileña del segundo tercio del siglo XVII. Madrid: Instituto Diego Velázquez, CSIC.

BONADUCE, I., CARLYLE, L., COLOMBINI, M.P. et al. (2012). “New Insights into the Ageing of Linseed Oil Paint Binder: A Qualitative and Quantitative Analytical Study. PLOS ONE 7, Issue 11, e49333, doi: 10.1371/journal.pone.0049333.

COLOMBINI, M.P., LANTERNA, G., MAIRANI, A. et al. (2001). “Copper resinate: preparation, characterization and study of degradation". Annali di Chimica, 91(11-12): 749-757.

COLOMINA SUBIELA, A. y GUEROLA BLAY, V. (2011-2012). "Resinatos de cobre: Estado de la cuestión y su debate entre la conservación y la eliminación". Arché. Publicación del Instituto Universitario de Restauración del Patrimonio de la UPV, 6-7: 69-74.

CRUZ VALDOVINOS, J.M. (1997): "Primer documento biográfico de Francisco Collantes". En Boletín del Seminario de Arte y Arqueología, tomo 63, pp. 447-451. <https://dialnet.unirioja.es/servlet/ 
articulo?codigo $=67606>$ [Consulta: 16 de noviembre de 2017].

DE LA VORÁGINE, S. (2011). La leyenda dorada. Madrid: Alianza Editorial.

DOERNER, M. (2011). Los materiales de pintura y su empleo en el arte. Barcelona: Editorial Reverté S. A, 18ª edición alemana actualizada por Thomas Hoppe.

EASTAUGH, N., WALSH, V., CHAPLIN, T. et al. (2008). Pigment Compendium: A Dictionary and Optical Microscopy of Historic Pigments. Amsterdam: Buterworth-Heinemamm, Elsevier Science.

ERHARDT D. (1998). "Paints Based on Drying-Oil Media", Painted Wood: History and Conservation, Proceedings, The Getty Conservation Institute, 17-32. En Painted Wood: History and Conservation, Dorge, V. y Carey Howlett, F. (eds.). Singapore: Paul Getty Trust, 17-32.

EXPOSICIÓN IBEROAMERICANA. Catálogo del Palacio de Bellas Artes. Sección de Arte. Antiguo, Imprenta de la Exposición, Sevilla, 1930.

KAAL, J., SCHELLEKENS, J., NIEROP, K.G.J. et al. (2014). “Contribution of organic matter molecular proxies to interpretation of the last 55 ka of the Lynch's Crater record (NE Australia)", Palaeogeography, Palaeoclimatology, Palaeoecology, 414: 20-31.

KOLATTUKUDY, P.E. (2001). "Polyesters in higher plants", Adv. Biochem. Eng. Biotechnol. 71: 1-49.

KÜHN, H. (1993). "Verdigris and Copper Resinate". En Artists" Pigments: A handbook of their History and Characteristics, Vol. II, Roy, A. (coord.). Oxford: Oxford University Press, 131-158.

LAZZARI, M. y CHIANTORE, O. (1999). "Drying and oxidative degradation of linseed oil." Polymer Degradation and Stability 65: 10.

MILLS J. S., WHITE R. (1987). The Organic Chemistry of Museum Objects. Oxford: Butterworths.

NIEROP, K.G.J.; VERSTRATEN, J.M. (2004). "Rapid molecular assessment of the bioturbation extent in sandy soil horizons under pine using ester-bound lipids by on-line thermally assisted hydrolysis and methylation-gas chromatography/mass spectrometry", Rapid Commun. Mass Spectrom., 18: 1081-1088.

PÉREZ SÁNCHEZ, A.E. (1962): "Algunas obras inéditas y nuevas consideraciones en torno a Collantes". En Archivo Español de Arte, Tomo XXXV, n 139, pp. 253-263.

ROBINET, L., SPRING, M., PÀGES CAMAGNA, S. (2011):"Investigation of the loss of color in smalt on degradation in paintings using multiple spectroscopic analytical techniques". Analytical Chemistry, 83: 5145-5152.

SANCHO CUBINO, N. (2004): Revisión y reproducción de los antiguos métodos de obtención de los pigmentos de cobre. Trabajo de investigación presentado para la obtención del Diploma de Estudios
Avanzados (DEA), Madrid: Departamento de Pintura (PinturaRestauración), Universidad Complutense de Madrid.

SANCHO, N., SANTOS, S., DE LA ROJA, J. et al. (2004). "Variación cromática del verdigrís en función de su método de obtención", Óptica Aplicada y Pura, 37(1): 119-123.

SANTOS GÓMEZ, S. SAN ANDRÉS MOYA, M., BALDONEDO RODRÍGUEZ, J.L. et al. (2003):"Recetas de preparación del verdigrís. Resultados preliminares de la obtención de la variedad conocida como viride salsum", Pátina, 12: 41-52.

SANTOS GÓMEZ, S., SAN ANDRÉS MOYA, M., BALDONEDO RODRÍGUEZ, J.L. et al. (2002): "Proceso de obtención del verdigrís. Revisión y reproducción de antiguas recetas. Primeros resultados". En I Congreso del GEIIC, Conservación del Patrimonio. Evolución y nuevas perspectivas, Valencia: Grupo Español del ICC, 383-388.

SPRING, M., HIGGIT, C., SAUNDERS, D. (2005). "Investigation of Pigment-Medium Interaction Process in Oil Paint containing Degraded Smalt". National Gallery Technical Bulletin, 26: 56-70.

VAN DEN BERG K J.V., EIKEMA HOMMES M.H.V., GROEN K.M. et al. (2000a). "On copper green glazes in painting", Art et Chimie. La couleur. Actes du congrès, Paris, pp. 18-21.

VAN DEN BERG, J.D.J., VAN DEN BERG, K.J., BOON, JJ. (2002). "Identification of non-cross-linked compounds in methanolic extracts of cured and aged linseed oil-based paint films using gas chromatography-mass spectrometry." Journal of Chromatography A, 950: 195-211.

VAN DEN BERG, K.J., BOON, JJ., PASTOROVA, I. et al.. (2000b). “Mass spectrometric methodology for the analysis of highly oxidized diterpenoid acids in Old Master Paintings", Journal of Mass Spectrometry, 35: 512-533.

VILLARQUIDE JEVENOIS, A. (2001). Restauración e Conservación de Pintura sobre tea. Alteracións, materiais e tratamentos. Ourense: Normal. Edicións de Arte.

VOORHEES, K.J. (2013). Analytical Pyrolysis: Techniques and Applications. Amsterdam: Butterworth-Heinemann. Elsevier.

\section{Autor/es}

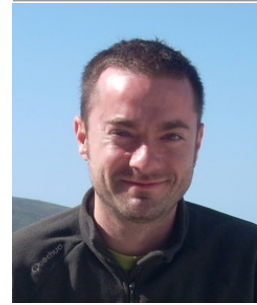

\section{Oscar Lantes-Suárez}

oscar.lantes@usc.es

Unidade de Arqueometría. RIAIDT. Universidad de Santiago de Compostela

Licenciado en Biología por la Universidad de Santiago de Compostela. Responsable de la Unidade de Arqueometría de la Universidad de Santiago de Compostela. Está especializado en el análisis de artefactos arqueológicos y bienes culturales y en 
el asesoramiento especializado y emisión de informes en estos ámbitos. Ha participado en diversas publicaciones científicas relacionadas con la alteración de rocas, caracterización de biofilms, análisis de residuos orgánicos y cuantificación del color en cerámicas, análisis de huesos, estudios de procedencia en líticos prehistóricos y cerámicas así como en otras publicaciones centradas en las aplicaciones de técnicas de análisis como la microscopía electrónica de barrido o la tomografía y radiografía de rayos $\mathrm{X}$.

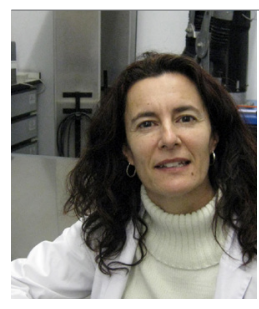

\section{Laura Carrera Nogueiras}

laura.carrera.nogueiras@xunta.gal

Museo de Belas Artes da Coruña

Diplomada en Conservación y Restauración de Bienes Culturales en la especialidad de Escultura por la Escuela Superior de Conservación y Restauración de Bienes Culturales de Galicia en Pontevedra. Diplomada en Magisterio en la especialidad de Ciencias Humanas por la Universidad de Vigo. Experto en Conservación Preventiva en Museos y Exposiciones por la Universidad de Alcalá de Henares. Restauradora del Museo de Belas Artes da Coruña desde el año 1999, donde realiza su actividad profesional como responsable del Laboratorio de Restauración. Ha participado como docente en el Máster en Técnicas de Gestión Integral del Patrimonio Cultural (2a edición-curso 2006-2007) organizado por la USC y CSIC en Santiago de Compostela.

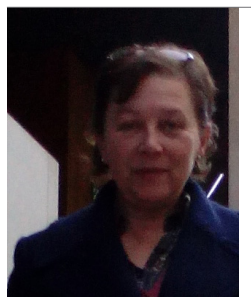

\section{Filo Dorrego Martínez}

filomena.dorrego.martinez@xunta.gal

Museo de Belas Artes da Coruña

Licenciada en Geografía e Historia (Especialidad Historia del Arte) por la Universidad de Santiago de Compostela. Pertenece desde el año 2003 al Cuerpo Facultativo Superior de la Xunta de Galicia, Especialidad de Museos. Trabaja desde el año 2006 en el Museo de Belas Artes da Coruña, donde realiza principalmente actividades relacionadas con la gestión documental de los fondos de la colección en el Departamento de Documentación. Con anterioridad, desarrolló su actividad profesional desde el año 1997 al 2004 en el Museo Arqueolóxico do Castro de Viladonga (Castro de Rei, Lugo).

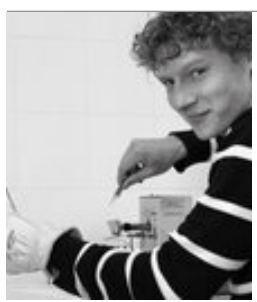

\section{Joeri Kaal}

joeri@samage.net

Instituto de Ciencias del Patrimonio (Incipit), Consejo Superior de Investigaciones Científicas (CSIC). Santiago de Compostela
Licenciado en Geografía Física en la Universiteit van Amsterdam. Doctoradoen Medio AmbienteeRecursos Naturais delaUniversidade de Santiago de Compostela, en base de una línea de investigación realizado en la USC y el Instituto de Ciencias del Patrimonio (CSIC, Santiago de Compostela) financiado con una beca Marie Curie del ERC (FP7). Su investigación se centra en aplicaciones de la química orgánica en diversas disciplinas incluyendo la arqueometría. En este sentido, tiene experiencia con la caracterización molecular de objetos arqueológicos como materiales de pintura, carbón vegetal, joyas de resina, azabache, colágeno, cerámica y una variedad de materiales vegetales excavadas de yacimientos, utilizando principalmente la pirólisis analítica

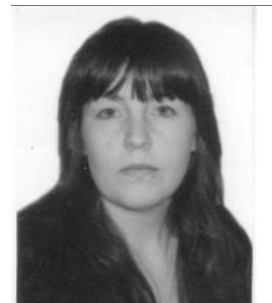

\section{Vanesa Mariño Calvo}

mariavanesa.marino.calvo@usc.es

Unidade de Arqueometría. RIAIDT. Universidade de Santiago de Compostela

Graduada en Historia del Arte con máster universitario en Arqueología y Ciencias de la Antigüedad por la Universidad de Santiago de Compostela. Miembro IFP en el grupo de investigación Síncrisis. Investigación en Formas Culturais (GI-1919SIFC), con una tesis versada en Historia Antigua. Actualmente goza de un contrato predoctoral por la Xunta de Galicia. Con anterioridad, su carrera profesional se desarrolló en el sector de la arqueología. Asimismo, ha participado en diversas publicaciones y encuentros para jóvenes investigadores y colabora con la Unidade de Arqueometría de la Universidad de Santiago de Compostela.

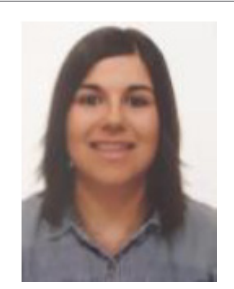

\section{Antonia Domínguez Lago}

tdl_gallega@hotmail.com

Unidade de Arqueometría. RIAIDT. Universidade de Santiago de Compostela

Colaboradora de la Unidade de Arqueometría de la Universidad de Santiago de Compostela, en Grado de Historia del Arte por esta misma Universidad así como Máster Interuniversitario en Arqueología y Ciencias de la Antigüedad por la Universidad de Santiago de Compostela, Universidad de Vigo y CSIC y también Máster Universitario en Profesorado de Educación Secundaria Obligatoria, Bachillerato, Formación Profesional y Enseñanza de Idiomas por la Universidad de A Coruña. Ha desarrollado prácticas en el Centro Centro Arqueolóxico do Barbanza, en la Unidade de Arqueometría de la Universidad de Santiago de Compostela y en el área de Geografía e Historia del IES Fontexería (Muros).

Artículo enviado el 27/02/2018 Artículo aceptado el 20/11/2018 